\title{
Change in Molten Metal Pressure and Its Effect on Defects of Aluminum Alloy Die Castings*
}

\author{
Yasushi Iwata, Shuxin Dong, Yoshio Sugiyama and Hiroaki Iwahori \\ Toyota Central R\&D Labs., Inc., Nagakute 480-1192, Japan
}

Surface defects of die castings, such as surface folds, cold shuts and misruns, etc., are thought to occur due to the solidification of molten metal during mold filling. In the die casting process, mold filling and solidification are completed under high pressure. Thus, varying the casting pressure may also have some effects on surface defects.

In this study, we investigated the effects of solidification on mold filling and pressure transmission and elucidated the influences of casting pressure on the quality of die castings.

In the mold filling process of JIS AC4C (A356) alloy (hereinafter called AC4C alloy), flow resistance was found to increase with the increase of the amount of solid phases, and thus decreased the velocity of molten metal flow. Cold shut occurred due to the rapid drop of the temperature of molten metal as a result of the decrease in flow velocity. A similar phenomenon was also observed for JIS AD12.1 (A38X) alloy (hereinafter called AD12.1 alloy), although this alloy showed a skin-formation type solidification. The pressure transmission in molten metal weakened gradually with the increase in the amount of solid phases and eventually stopped completely to cause casting defects as the result. In addition, resistance to molten metal flow due to the back pressure, shape of mold cavities, etc., was also noticed. These results indicate that a high plunger pressure is necessary to obtain die castings without defects. [doi:10.2320/matertrans.F-M2013838]

(Received September 2, 2013; Accepted November 6, 2013; Published December 20, 2013)

Keywords: aluminum, alloy, die casting, pressure transmission, solidification, defects, surface folds, cold shut, misrun

\section{Introduction}

Die casting, which features high-velocity and highpressure mold filling by molten metal, is a highly productive manufacturing method for castings of intricate shapes. However, casting defects often occur in this process because of the high-velocity filling of molten metal. For example, blowholes result from the entrapment of gases in the cavity in the filling molten metal, ${ }^{1-7)}$ while surface folds, cold shuts and misruns arise from the temperature drop of the filling molten metal. ${ }^{8)}$ It is also known that all of the above casting defects can be alleviated by increasing the casting pressure. Therefore, it is important to optimize the mold filling process and to ensure the transmission of the casting pressure to guarantee the quality of die castings. ${ }^{9-14)}$

Recently, high properties have become increasingly essential for die castings and the alloy for die casting is not limited to conventional JIS ADC12.1(A38X) alloy but is also extended to JIS AC4C(A356) alloy, which has better ductility. However, AC4C alloy is known as a difficult-tocast material. Thus, it is necessary to understand the mold filling behavior of this alloy during die casting to guarantee the quality of castings.

For the purpose of energy saving, the miniaturization of die casting machines is being promoted and lowering casting pressure while suppressing defects is a key technology. A high casting pressure can reduce blowholes and surface defects. ${ }^{9,10)}$ Because simply lowering casting pressure influences the quality of die castings, it is important to clarify the limiting factors in pressure transmission in molten metal during the die casting process and the relationship between casting pressure and defects.

In this research, factors affecting the pressure transmission in molten metal in the die casting process were investigated

*This Paper was Originally Published in Japanese in J. JFS 84 (2012) 618623. with two kinds of alloys (AC4C and AD12.1), which have different solidification styles, and the effects of the solidification styles of these casting alloys on the quality of die castings were revealed.

\section{Experimental and Simulation Methods}

\subsection{Experimental die castings and casting methods}

Two kinds of mold cavities, shown in Fig. 1, were prepared for investigating surface defects and blowhole defects of die castings. The type A cavity in Fig. 1 was used for examining the effect of solidification on mold filling and the occurrence of the cold shut defect. In the mold filling process of this cavity, molten metal flowing from the right and the left sides ran into each other at the top part of the cavity. AC4C alloy (Al-7 mass $\% \mathrm{Si}-0.3$ mass $\% \mathrm{Mg}$ ) was used in the casting of this cavity to examine the cold shut defect, which especially occurs in castings made of this alloy due to its poor fluidity compared with that of AD12.1. The injection temperature of molten metal was changed from 963 to $993 \mathrm{~K}$. The temperature and pressure of the flowing molten metal in the cavity were measured at the positions shown in Fig. 1.

The type B cavity in Fig. 1 was used to investigate the effect of temperature drop of molten metal on the pressure transmission from the plunger and the relationship between pressure transmission and the formation of blowholes. The type B cavity had the following dimensions: length $120 \mathrm{~mm}$, width $40 \mathrm{~mm}$ and thickness $5 \mathrm{~mm}$. The molten metal was injected from the sleeve and flowed through the runner and the gate upwards sequentially to fill the cavity. The gate was set as narrow as $2 \mathrm{~mm}$. Thus, when molten metal entered the cavity through the gate, it would be disturbed and entrap gases to form blowholes. In this experiment, the temperature and pressure of molten metal were measured at the vicinity of the gate, and the effect of molten metal solidification on pressure transmission was investigated for casting pressures from 30 to $65 \mathrm{MPa}$. AD12.1 alloy (Al-11.6 mass\%Si- 

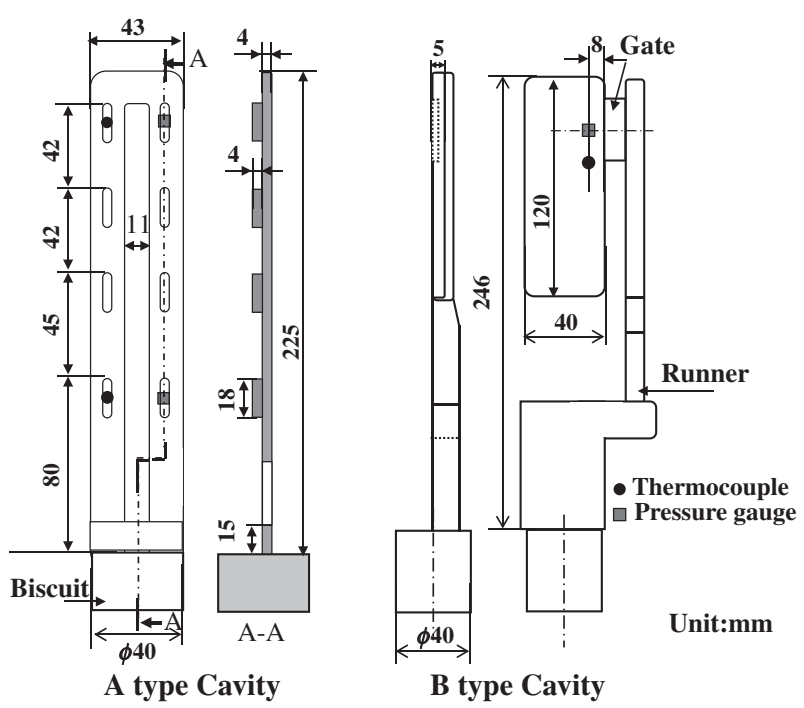

Fig. 1 Dimension of cavity for experiment.

2.8 mass $\% \mathrm{Cu}-0.2$ mass $\% \mathrm{Mg}$ ), the most typical alloy for die casting in Japan, was used for this experiment and molten metal was injected at $913 \mathrm{~K}$. The internal defects of the experimental castings were assessed by X-ray photos.

The temperature of molten metal in the cavity was measured by the detachable high-response temperature sensor made of a $\phi 0.1 \mathrm{~mm}$ CA thermocouple protected by a ceramic tube, and the tip of the temperature sensor was set at the center of the thickness of the cavity. The position of the plunger was monitored by the change in the electrical resistance of a potentiometer.

\subsection{Simulation method of mold filling}

To verify the measured results of the type A cavity in Fig. 1, the mold filling process of the same die casting was simulated by the commercial software, TOPCAST (TCS Co. Ltd.). In the simulation, the injection temperature and the injection velocity of molten metal in the sleeve were $963 \mathrm{~K}$ and $0.26 \mathrm{~m} / \mathrm{s}$, respectively. The interfacial heat transfer coefficient between the molten metal and the mold was $6700 \mathrm{~W} / \mathrm{m}^{2} / \mathrm{K}$. The analyses of mold filling and heat transfer were performed simultaneously. The viscosity coefficient of the molten metal was estimated by another experiment as a function of the temperature of molten metal during solidification $^{15)}$ and changed according to the solid fraction of molten metal in the analysis. The pressure of molten metal was calculated by the Navier-Stokes equation and the continuity equation.

In approaching the situation of practical castings, the model of the shape shown in Fig. 2 was used to examine the factors affecting the pressure of molten metal. The mold filling process was analyzed by the commercial software, FLOW3D (Flow Science Inc.) with the shape model divided by $2.5 \mathrm{~mm}$ meshes. The initial temperature and the injection velocity of molten metal in the sleeve were $893 \mathrm{~K}$ and $3 \mathrm{~m} / \mathrm{s}$, respectively, and the properties of $\mathrm{AD} 12.1$ alloy were adopted in the analysis. To see the effect of the back pressure, the pressures of gases at positions a, b, c and $d$ in Fig. 2 were changed to two levels: atmospheric pressure $(0.1 \mathrm{MPa})$ and reduced pressure $(0.0026 \mathrm{MPa})$. The variation

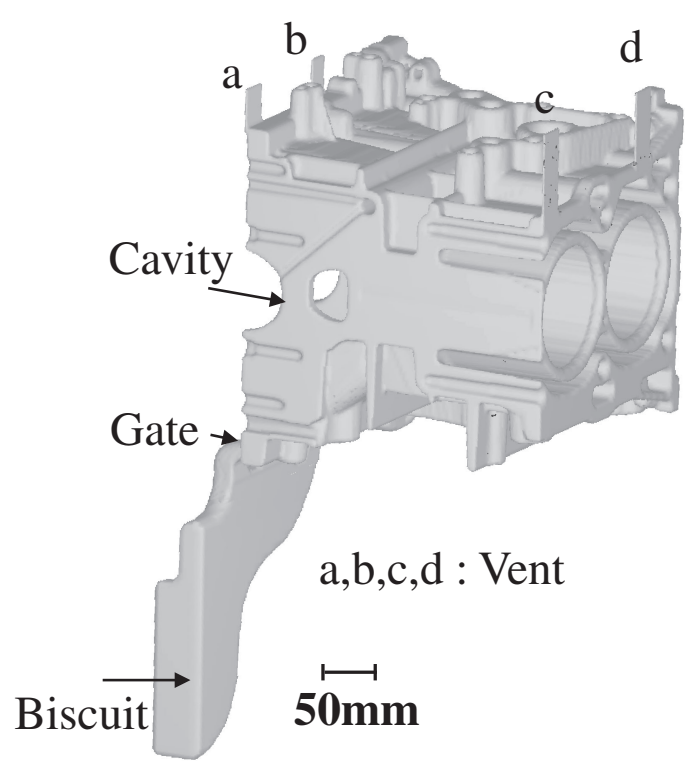

Fig. 2 Die casting for mold filling simulation.

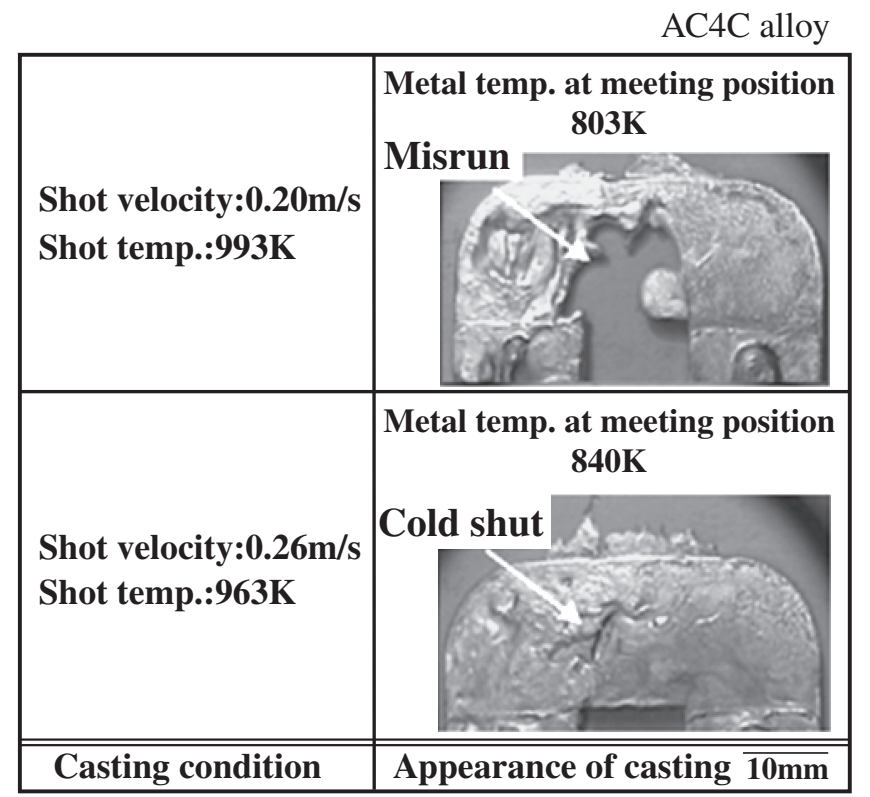

Fig. 3 Appearances of die castings.

of the resistance to flowing molten metal with the progress of solidification was measured in another experiment and was taken into account in the form of the viscosity coefficient.

\section{Results and Discussions}

\subsection{Molten metal pressure of AC4C alloy during mold filling and the quality of the die casting}

The appearances of castings made by injecting the molten metal of AC4C alloy into the type A cavity of Fig. 1 under various conditions are shown in Fig. 3, which focuses on the areas where the tips of flowing molten metal collided during mold filling. Misrun and cold shut defects occurred in the top area of the casting, where the tips of flowing molten metal collided after the temperature of the tips of flowing molten metal decreased. To elucidate the relationship between the 

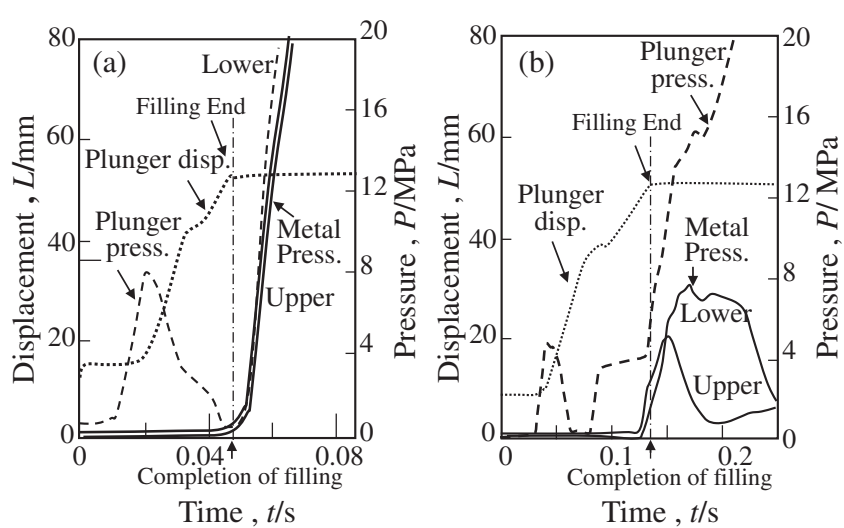

Fig. 4 Pressure curves of plunger and molten metal; (a) Casting without cold shut (Shot vel.: $1.0 \mathrm{~m} / \mathrm{s}$, shot temp.: $963 \mathrm{~K}$ ) (b) Casting with cold shut (Shot vel.: $0.26 \mathrm{~m} / \mathrm{s}$, shot temp.: $963 \mathrm{~K}$ ).

cold shut defect and the solidification of flowing molten metal, the pressure change of molten metal from the start to the end of mold filling was analyzed by comparing the displacement and the pressure of the injection plunger.

The castings made under the conditions that the cold shut defect did not occur (injection temperature, injection velocity and casting pressure were $963 \mathrm{~K}, 1 \mathrm{~m} / \mathrm{s}$ and $65 \mathrm{MPa}$, respectively) and occurred (injection temperature, injection velocity and casting pressure were $963 \mathrm{~K}, 0.26 \mathrm{~m} / \mathrm{s}$ and $65 \mathrm{MPa}$, respectively) are shown in Figs. 4(a) and 4(b). The time at which the displacement of the plunger became constant on the displacement curve was taken as the finish time of mold filling. A noticeable difference between (a) and (b) in Fig. 4 was observed in the pressures of molten metal at the end of mold filling, i.e., a rapid increase to as high as $20 \mathrm{MPa}$ was seen in (a), while only a comparatively slow increase to 5 or $8 \mathrm{MPa}$ was seen in (b). At the same time, differences between the rising time of plunger pressures and molten metal pressures were also observed before the end of mold filling. Therefore, the details of the position, the pressure of the plunger and the corresponding pressure of molten metal were further examined around the end of the mold filling.

The pressures of the molten metal and the plunger are shown in Fig. 5 in relation to the moving distance of the plunger from the position of the end of mold filling. Under casting condition (a), no surface folds occurred and the pressure of the moving plunger was as low as $1 \mathrm{MPa}$. Although the molten metal pressure at the upper part was slightly higher than that of the lower part, both were below $0.5 \mathrm{MPa}$. Under casting condition (b), cold shut occurred on the castings and the pressure of the plunger was kept as high as $4 \mathrm{MPa}$ almost until the end of mold filling, i.e., at the position of $-0.5 \mathrm{~mm}$ before stopping. The pressure of molten metal stayed at almost a constant low value of $0.5 \mathrm{MPa}$ before arriving at the position of $-2.0 \mathrm{~mm}$, and then the pressure began to increase to a value of $2.5 \mathrm{MPa}$ at the upper part and a value of $2 \mathrm{MPa}$ at the lower part of the cavity when the plunger stopped.

The measured results are explained as follows. The lower part of the cavity near the sleeve is continuously fed with hotter molten metal and the temperature drop is small.

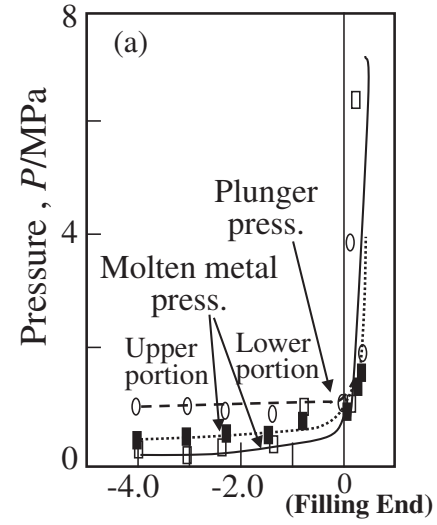

Distance from Top Dead Center, $L / \mathrm{mm}$

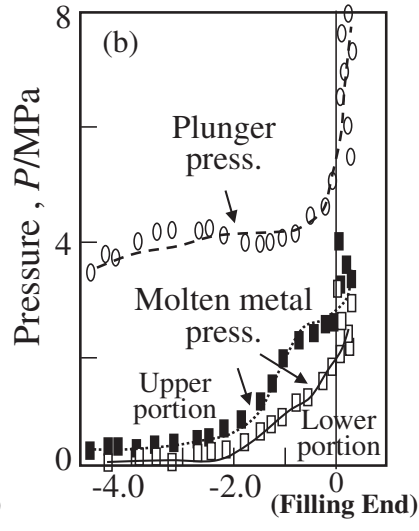

Distance from Top Dead Center , $L / \mathrm{mm}$
Fig. 5 Molten metal pressure just before the completion of filling; (a) Casting without cold shut (Shot vel.: $1.0 \mathrm{~m} / \mathrm{s}$, shot temp.: $963 \mathrm{~K}$ ) (b) Casting with cold shut (Shot vel.: $0.26 \mathrm{~m} / \mathrm{s}$, shot temp.: $963 \mathrm{~K}$ ).

Because the upper part of the cavity is far from the sleeve, the temperature drop of molten metal is large, and the solidification of molten metal progresses with the mold filling. As the solidification of molten metal progresses, the solid fraction of molten metal increases and the resistance to the flow of molten metal also increases. Thus, a higher pressure is needed for the successive mold filling. That is, under the condition that cold shut occurs, the temperature drop of flowing molten metal is large and the solidification of molten metal progresses. Thus, a higher pressure is necessary for successive mold filling in comparison with the condition that cold shut does not occur. As a result, it is considered that the difference between the pressures of the upper part and the lower part becomes large under the condition that cold shut occurs.

The simultaneous simulation of molten metal flow and heat transfer during mold filling was carried out and the calculated pressure distribution in molten metal just prior to the end of mold filling is shown in Fig. 6. The calculated result is illustrated in Fig. 6(a), in the case that no cold shut occurs, i.e., the resistance to flowing molten metal does not increase with the progress of solidification. Thus, a constant kinematic viscosity coefficient is assumed. The pressure of the molten metal filling the cavity hardly increases and the pressure at the apex part of the casting corresponding to the tip of flowing molten metal is as low as 0.1 to $0.2 \mathrm{MPa}$. The pressure in the plunger is also as low as 0.3 to $0.4 \mathrm{MPa}$. The calculated result is shown in Fig. 6(b): when cold shut occurs, the resistance to flowing molten metal increases with the increase of solid phases along with the progress of solidification. Thus, an increasing kinematic viscosity coefficient is assumed. In this case, the pressures of molten metal both in the plunger and at the apex part of the casting are at high levels of 2.8 to $2.9 \mathrm{MPa}$ and 2.9 to $3.0 \mathrm{MPa}$, respectively. This value of the pressure at the apex part is higher than that at the central part of the casting. The calculated and the measured values of the pressure at the apex part of the casting are compared in Fig. 7 when cold shut occurs. It is shown that the calculated pressure is in good agreement with the measured value by taking into account 
(a)

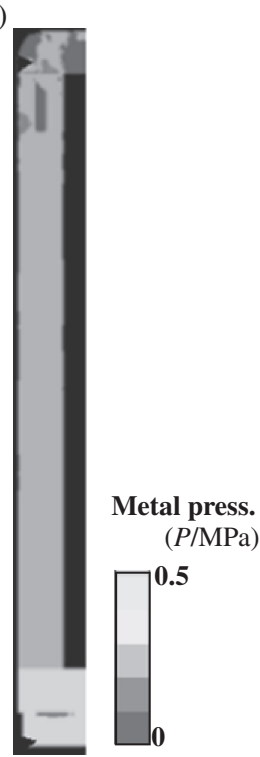

(b)

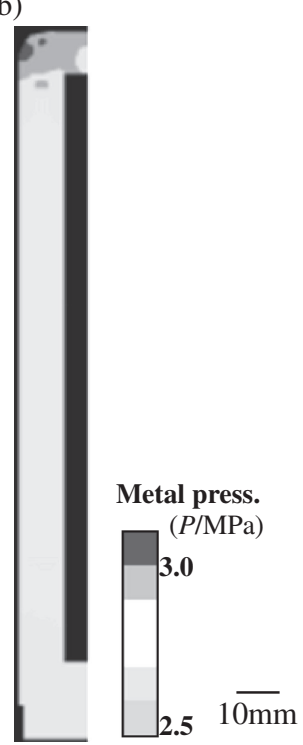

Fig. 6 Distribution of molten metal pressure just before the completion of filling; (a) Ignoring viscous behaviour (b) Considering viscous behaviour.

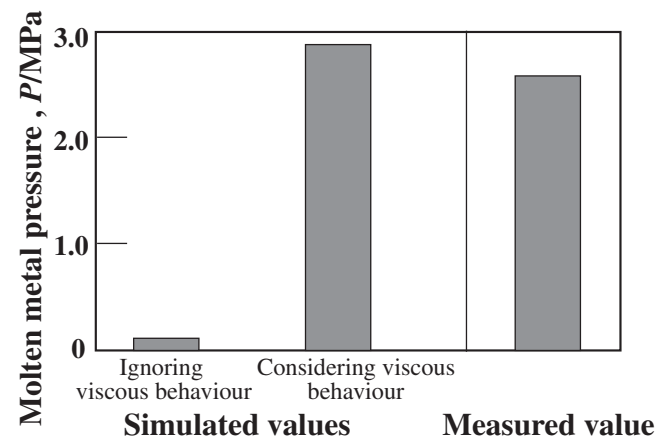

Fig. 7 Molten metal pressure at biscuit just before the completion of filling.

the effect of the kinematic viscosity coefficient. That is, the increase of the pressure of flowing molten metal comes from the rise of its flowing resistance due to the increment of its apparent viscosity with the progress of solidification.

The calculated flow velocities of molten metal at different positions of the mold cavity are illustrated in Fig. 8. The flow velocity at the position of $120 \mathrm{~mm}$ from the biscuit is almost the same for each of the cases with or without considering the viscosity change of molten metal, but the flow velocity of molten metal at the position of $220 \mathrm{~mm}$ from the biscuit decreases abruptly with the increase of molten metal pressure at the apex part of the cavity for the case considering the viscosity change of molten metal. That is, the pressure necessary for mold filling increases and the velocity of molten metal decreases abruptly due to the rise of the resistance to the tip of the molten metal flow with the progress of solidification, and the result is the occurrence of cold shut.

\subsection{Effect of solidification on the pressure transmission in molten metal and the quality of castings}

The pressure of the plunger, the temperature and the pressure of molten metal in the cavity near the gate are shown in Fig. 9 when making the casting illustrated as type B of

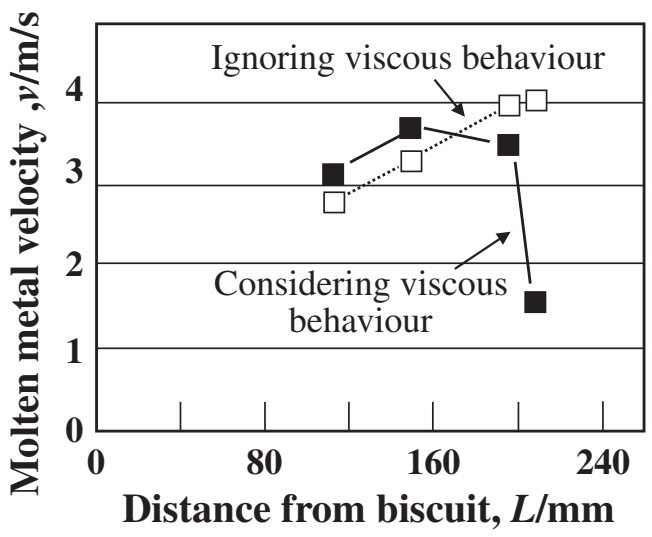

Fig. 8 Change of molten metal velocity with filling rate.
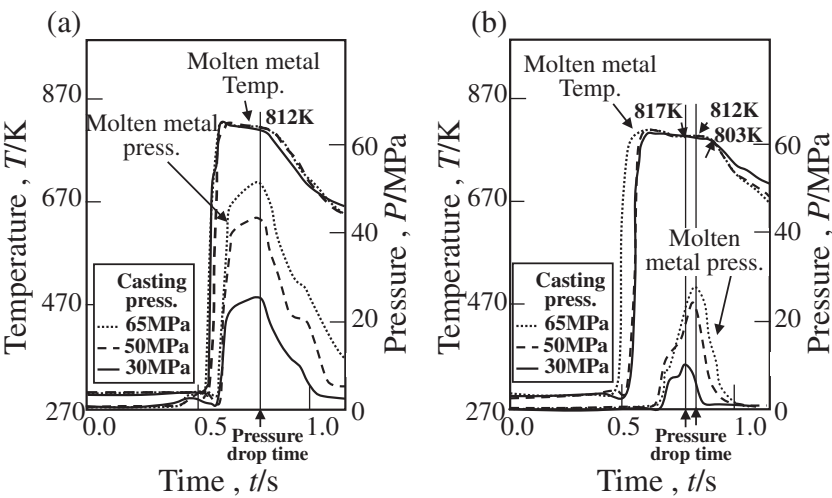

Fig. 9 Changes of molten metal pressure and temperature during pressurization; (a) Shot velocity: $0.8 \mathrm{~m} / \mathrm{s}$ (b) Shot velocity: $0.2 \mathrm{~m} / \mathrm{s}$.

Fig. 1 with different injection velocities $(0.8$ and $0.2 \mathrm{~m} / \mathrm{s})$ and different casting pressures $(65,50$ and $30 \mathrm{MPa})$. For all of the casting pressures, molten metal reaching the point of the thermocouple showed a temperature of $823 \mathrm{~K}$, near the eutectic temperature. After that, molten metal cooled gradually to approximately $803 \mathrm{~K}$ and then quickly to a lower temperature. In the range of casting pressures of this research, all of the molten metal showed almost the same cooling behaviors described above. The pressure of molten metal rose rapidly at the end of mold filling and showed a small increase during cooling of the molten metal in the cavity. The pressure of molten metal decreased rapidly when the temperature reached $812 \mathrm{~K}$. Therefore, it can be concluded that at the time when the temperature of molten metal reached $812 \mathrm{~K}$, the pressure transmission in the molten metal was blocked at the position of the gate. For all of the casting pressures, the pressure change of molten metal showed the same tendency during casting, although the pressure values themselves were different. Especially, in the case of the injection velocity of $0.8 \mathrm{~m} / \mathrm{s}$, despite the different values of casting pressure, the pressure transmission in molten metal continued until the molten metal reached the same solidification state $(812 \mathrm{~K})$.

For the injection velocity of $0.2 \mathrm{~m} / \mathrm{s}$, the pressure in molten metal decreased gradually until the temperature of molten metal reached approximately $803 \mathrm{~K}$ and then it decreased quickly after that. Under the casting conditions of this research, despite the difference in casting pressures, molten metal showed almost the same cooling behavior. The 


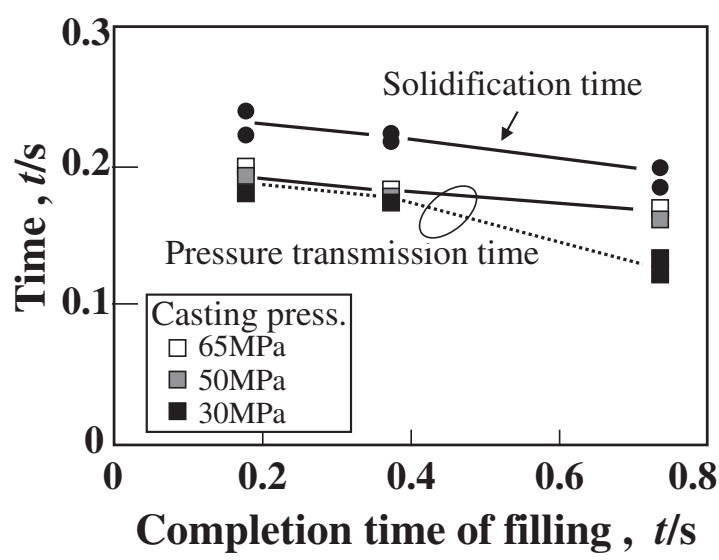

Fig. 10 Relationship between pressure transmission time and completion time of filling.

pressure of molten metal rose rapidly at the end of mold filling and then rapidly decreased in a short time. However, the time when the pressure of molten metal rapidly decreased was different and depended on the casting pressure. The turning point of molten metal pressure came when the temperature of molten metal reached approximately $812 \mathrm{~K}$ for casting pressures of 50 and $65 \mathrm{MPa}$, while the turning point occurred when the temperature of molten metal decreased to $817 \mathrm{~K}$ for the casting pressure of $30 \mathrm{MPa}$. Under the conditions of this research, the pressure transmission in molten metal stopped in an earlier stage as the casting pressure was lowered to $30 \mathrm{MPa}$.

The pressure transmission time in molten metal is shown in Fig. 10 for different casting pressures when the injection velocity was set to $0.8,0.4$ and $0.2 \mathrm{~m} / \mathrm{s}$ with the corresponding mold filling time of $0.2,0.4$ and $0.74 \mathrm{~s}$. The time between the end of mold filling and the stop of pressure transmission in molten metal as its temperature reached $812 \mathrm{~K}$ (for casting pressure $30 \mathrm{MPa}$ ) was defined as the solidification time, as shown in Fig. 10. The time between the completion of mold filling and the finish of solidification (i.e., solidification time in Fig. 10) became short when mold filling time was extended due to the temperature drop of molten metal during mold filling. When the casting pressure was set to 65 and $50 \mathrm{MPa}$, the pressure transmission time in molten metal was shortened almost in proportion to the shortened part of the solidification time. On the other hand, when casting pressure was set as low as $30 \mathrm{MPa}$, the pressure transmission time shortened drastically as the mold filling time was extended to $0.74 \mathrm{~s}$. From the above experimental results, it is understood that the pressure transmission in molten metal becomes difficult due to the solidification at the gate if the solidification progresses drastically during mold filling, and for the casting pressure of $30 \mathrm{MPa}$, the pressurization cannot be continued.

The ratio of the maximum molten metal pressure to the corresponding plunger pressure, defined as the pressure transmission ratio in molten metal, is shown in Fig. 11 at the mold filling time of $0.74 \mathrm{~s}$. When the casting pressure was 50 and $65 \mathrm{MPa}$, half of the plunger pressure was transmitted to the molten metal in the cavity. However, if the casting pressure was decreased to $30 \mathrm{MPa}$, only 30 percent of the plunger pressure was transmitted to molten metal. Here, the

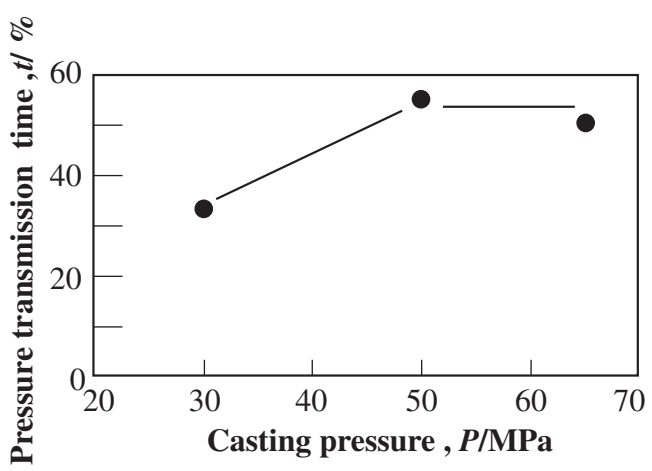

Fig. 11 Relationship between pressure transmission time and casting pressure. (a)

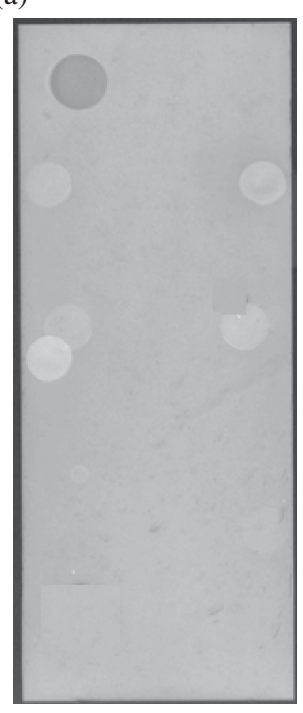

(b)

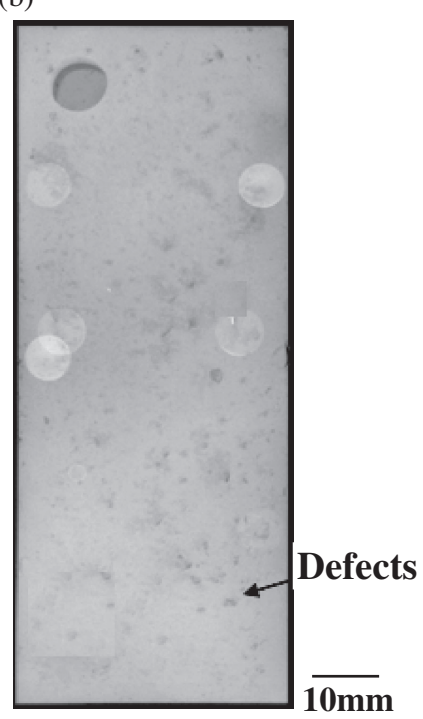

Fig. 12 Distribution of defects in castings made with different casting pressures; (a) Casting press.: $50 \mathrm{MPa}$ (b) Casting press.: $30 \mathrm{MPa}$.

injection velocity of $0.2 \mathrm{~m} / \mathrm{s}$ corresponds to a gate velocity as high as $20 \mathrm{~m} / \mathrm{s}$, at which a large amount of gases is expected to be entrapped into the molten metal. The transparent X-ray photo of this casting is shown in Fig. 12. Many internal defects, which are hardly found in the casting made under a casting pressure of $50 \mathrm{MPa}$, can be observed in Fig. 12. The compression effect of the casting pressure on entrapped gases can be calculated by this method, as reported in previous papers. ${ }^{9,10)}$ The calculated volume increase of the entrapped gases due to the decrease of molten metal pressure is in agreement with the result of the previous papers.

\subsection{Effect of the cavity shape and the back pressure on the flow resistance to molten metal during mold filling}

In the previous section, it was found that a high pressure is necessary for mold filling and molten metal feeding due to the increase of flow resistance resulting from the solidification of molten metal. However, in the mold filling process of practical castings, which generally have intricate shapes, the effects of cavity shape and back pressure on flow resistance should also be considered in addition to the effect of the solidification of molten metal. Therefore, an 


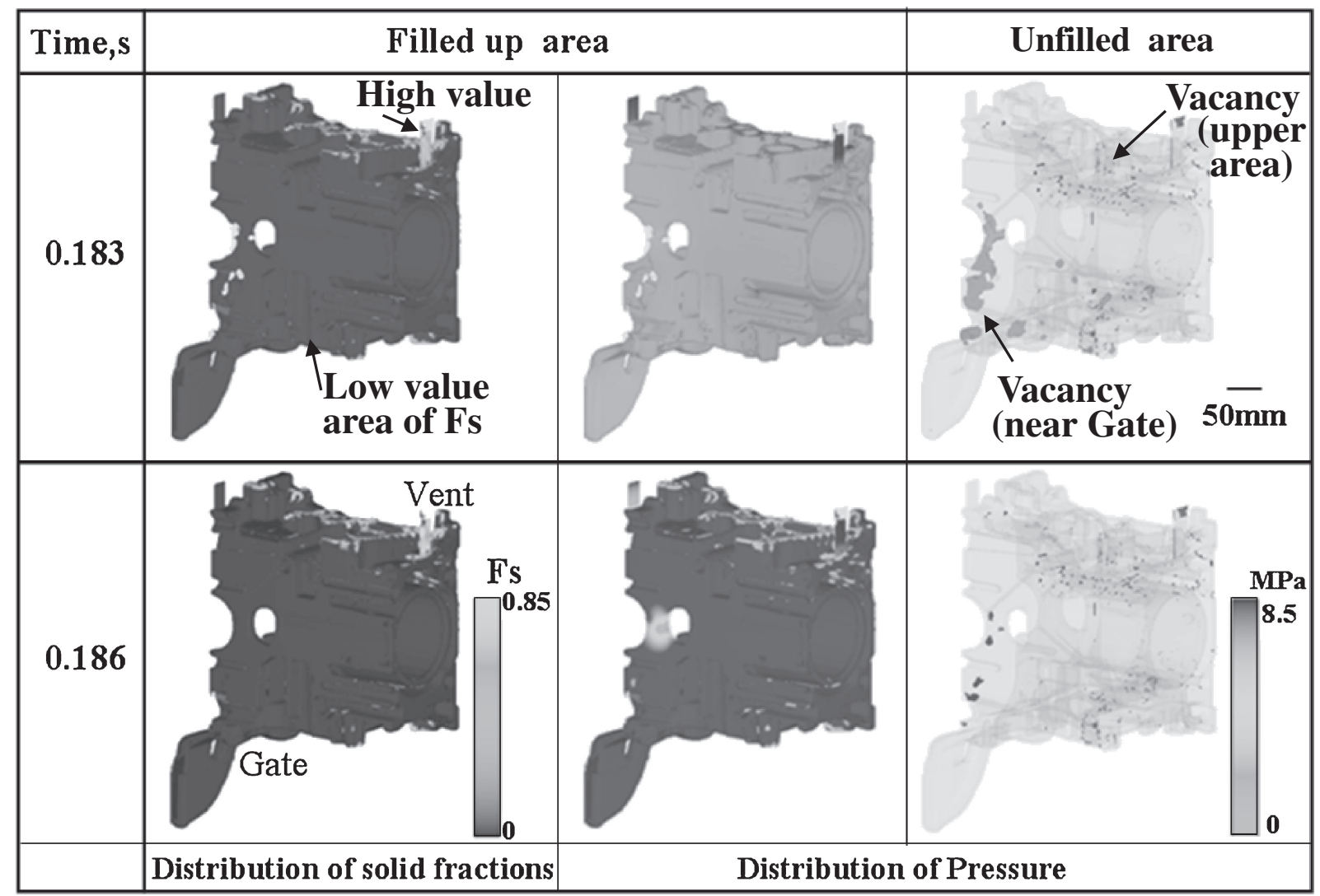

Fig. 13 Filling sequence of cavity just before the completion of filling.

experimental model simulating the shapes of practical castings was prepared and used to examine the effects of cavity shape and back pressure together with the solidification of molten metal on flow resistance by simulation.

The simulated variations of a solid fraction with time, the distribution of molten metal pressure and unfilled regions of the cavity from $0.183 \mathrm{~s}$ prior to the end of mold filling are shown in Fig. 13, when the pressure outside the gas vent was assumed to be atmospheric pressure $(0.1 \mathrm{MPa})$. The temperature drop of molten metal is small and the whole cavity is almost filled by the liquid phase at $0.183 \mathrm{~s}$ prior to the end of mold filling, although a large unfilled region in the vicinity of the gate and a small unfilled region in the upper part of the cavity are observed. However, in the upper part of the cavity near the gas vent, a small region of the high solid phase fraction begins to appear. The pressure of molten metal, approximately $2 \mathrm{MPa}$ at $0.183 \mathrm{~s}$, increases to $8 \mathrm{MPa}$ at $0.186 \mathrm{~s}$ prior to the end of mold filling. At this time, the unfilled region in the upper part of the cavity, where the solid fraction has arrived at a high level, hardly decreases, although that near the gate decreases greatly. The pressure of the unfilled region near the gate is equal to the pressure of the molten metal. Thus, it is speculated that this unfilled region was filled greatly and compressed by the increase of molten metal pressure. On the other hand, the pressure of the unfilled region in the upper part of the cavity did not change from 0.183 to $0.186 \mathrm{~s}$. Therefore, it is suggested that no molten metal feeding to this region occurs due to the increase of flow resistance coming from the solidification of molten metal, etc. In other words, a pressure high enough in molten metal should be maintained to compress the

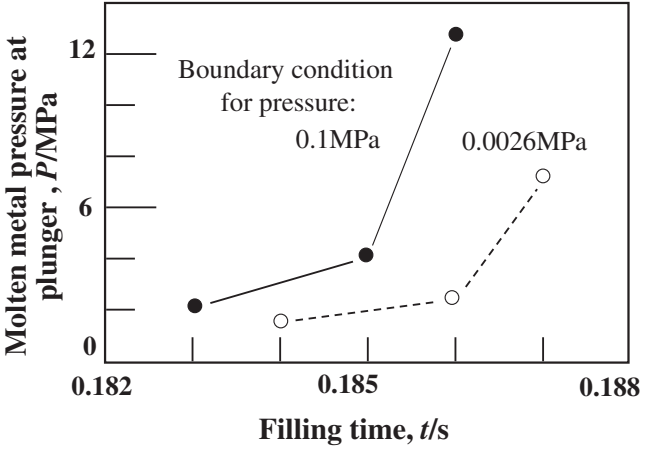

Fig. 14 Change in molten metal pressure at plunger just before the completion of filling.

entrapped gases in castings. Thus, pressurization from the plunger is necessary.

The pressures of the plunger necessary for mold filling, considered as the maximum pressure exerted on the biscuit at the end of mold filling, are calculated and shown in Fig. 14 when the outside boundary condition of the gas vent is taken as atmospheric pressure $(0.1 \mathrm{MPa})$ and reduced pressure $(0.0026 \mathrm{MPa})$. When the outside pressure of the gas vent is assumed as $0.1 \mathrm{MPa}$, the pressure necessary for mold filling rises due to the increase of back pressure at an early stage. If the outside pressure of the gas vent is reduced to $0.0026 \mathrm{MPa}$, back pressure does not increase even at the time of $0.186 \mathrm{~s}$, which is near the end of mold filling. Thus, the plunger pressure necessary for mold filling is comparatively low. In this case, the pressure at the biscuit increases to a maximum of $2 \mathrm{MPa}$ and it is assumed that a plunger pressure higher 
than $2 \mathrm{MPa}$ is necessary to finish mold filling. So, for the casting of an intricate shape like that of this research, a pressure of at least $2 \mathrm{MPa}$ is estimated to be necessary to overcome the flow resistance, including that from the cavity shape, thus preventing defects such as misrun, etc.

\section{Conclusions}

We examined the factors affecting the pressure of molten metal during mold filling and their effects on the formation of surface and inside defects of castings. We reached the following conclusions.

(1) If the temperature of molten metal drops drastically during mold filling, the pressure of molten metal rises and the flow velocity of the tip of molten metal decreases due to the increase of flow resistance resulting from the increase of the viscosity of molten metal. The cold shut defect occurs if the tip of the molten metal cools quickly due to the decrease of the flow velocity of molten metal. If the casting pressure is inadequate, it cannot be transmitted in the molten metal due to the high flow resistance, and thus results in misrun defects.

(2) Even for AD12.1 alloy, if the solidification of molten metal progresses to a high solid fraction and the casting pressure is inadequate, pressure cannot be transmitted in the molten metal, i.e., the molten metal cannot be fed from the plunger because of the flow resistance from solid phases. This insufficient feed of molten metal is the primary cause of inside defects such as blowholes.

(3) For castings of intricate shapes, a high plunger pressure is necessary to overcome the flow resistance coming from the shapes of castings. In addition, the increase of back pressure also becomes flow resistance during mold filling, and so it also should be considered in the casting pressure to avoid surface defects such as misruns and cold shuts, etc.

\section{REFERENCES}

1) Y. Iwata, Y. Yamamoto, M. Nakamura, K. Mizuno and S. Tsuboi: J. Jpn. Inst. Light Met. 39 (1989) 550-554.

2) Y. Iwata, K. Tozawa, Y. Yamamoto, M. Nakamura, K. Mizuno and M. Tsuboi: J. Jpn. Inst. Light Met. 37 (1987) 48-52.

3) Y. Yamamoto, Y. Iwata and M. Nakamura: IMONO 60 (1988) 770776.

4) E. Kato, A. Kokitsu, K. Ueda, H. Nomura and Y. Maeda: J. JFS 70 (1998) 103-108.

5) Y. Yamamoto, Y. Iwata, K. Tozawa and M. Nakamura: J. Jpn. Inst. Light Met. 38 (1988) 129-133.

6) Y. Yamamoto, Y. Iwata and M. Nakamura: J. Jpn. Inst. Light Met. 39 (1989) 21-24.

7) Y. Iwata, Y. Sugiyama, H. Iwahori and Y. Awano: J. JFS 72 (2000) 263-267.

8) Y. Iwata, K. Tozawa, Y. Yamamoto, M. Nakamura and K. Sasaoka: J. Jpn. Inst. Light Met. 36 (1986) 10-14.

9) Y. Iwata, S. Dong, Y. Sugiyama and H. Iwahori: J. JFS 83 (2011) 421426.

10) Y. Iwata, S. Dong, Y. Sugiyama and H. Iwahori: Mater. Trans. 53 (2012) 483-488.

11) S. Tanikawa, K. Asai, Y. Yang, H. Nomura and E. Kato: Rep. JFES Meeting 139 (2001) 134

12) Y. Sugiyama, H. Iwahori, K. Yonekura and Y. Ookochi: IMONO 66 (1994) 412-417.

13) N. Nishi, H. Sasaki, T. Hirahara and Y. Takahashi: IMONO 60 (1988) 777-783.

14) Y. Iwata, K. Tozawa, Y. Yamamoto and M. Nakamura: ALUMINIUM 63 (1987) 66-69.

15) Y. Iwata: Research Report No. 83 (JFES) (2000) pp. 35-41. 